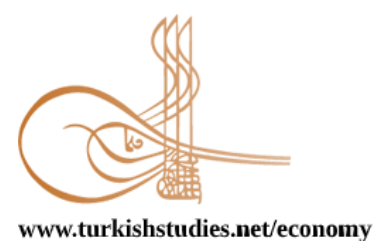

www.turkishstudies.net/economy

\section{Turkish Studies - Economics, Finance, Politics}

eISSN: 2667-5625

Research Article / Araștırma Makalesi

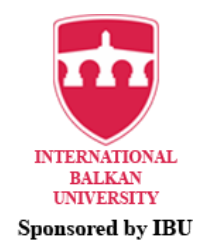

Sponsored by IBU

\title{
Örgütsel Desteğin İşe Tutkunluk Üzerine Etkisi: Beyaz Yakalı Çalışanlar Üzerine Bir Araştırma*
}

\author{
Effect of Organizational Support on Work Engagement: A Research on White Collar Employees
}

\author{
Meral Bektaş** - Şerife Karagöz ${ }^{* * *}$
}

\begin{abstract}
Organizations need qualified manpower to gain competitive advantage in the changing environmental conditions and globalization process. It is an undeniable fact that the concepts of organizational support and work engagement increase the performance of organizations and employees. The perception of organizational support provided especially to the employees within the organization creates a positive working environment by increasing the employee's attachment to the job, and thus, it becomes easier for the organization to reach its goals and objectives with the support provided. Accordingly the perception of organizational support, which is an important source of motivation for employees, can affect the tendency of employees' work engagement. The aim of this study is to examine the effect of organizational support on the perception of work engagement in white-collar employees in enterprises operating in Antalya. In the research, a questionnaire form was used as a data collection tool. The questionnaire consists of organizational support and work engagement scale, and demographic (gender, marital status, age, educationl status, working hour) questions. The data were collected by the snowball sampling method. The collected data were analyzed using SPSS 22.0 program. Descriptive statistics, pearson correlation and simple linear regression analysis were used to analyze the data. As a result of the research findings, it was determined that organizational support had an impact on work engagement behavior. In addition, while the dimensions of vigor and dedication have an effect on organizational support, it is determined that organizational support has no effect on the concentration dimension of business concentration. As a result of the research, it was found that as the support provided by the organization increases, the employees' passion for their work also increased.
\end{abstract}

Structured Abstract: In the globalizing world, human resources are one of the factors that enable businesses to survive, achieve competitive advantage and increase their success. Because the main element that will increase the success of the organizations is the organization employees. In the business world, where it is difficult to achieve sustainable competitive advantage today, organizations strive to increase their efficiency

\footnotetext{
*3-4 Kasım 2017 tarihinde 5. Ulusal Örgütsel Davranış Kongresi’nde özet kısmı sözlü bildiri olarak sunulmuştur.

** Dr. Öğr. Üyesi, Burdur Mehmet Akif Ersoy Üniversitesi, Asst. Prof. Dr., Burdur Mehmet Akif Ersoy University, Vocational School of Social Sciences, Office Services and Secretarial Department ORCID 0000-0002-1616-8065

mbektas@mehmetakif.edu.tr

**** Doktora Öğrencisi, Süleyman Demirel Üniversitesi, Sosyal Bilimler Enstitüsü, İşletme Anabilim Dalı PhD Student, Süleyman Demirel University, Institute of Social Sciences, Department of Business Administration ORCID 0000-0002-2542-1026

srfkrgz1992@gmail.com
}

Cite as/ Atıf: Bektaş, M. \& Karagöz, Ş. (2020). Örgütsel desteğin işe tutkunluk üzerine etkisi: Beyaz yakalı çalışanlar üzerine bir araştırma. Turkish Studies - $\quad$ Economy, 15(3), 1215-1231. https://dx.doi.org/10.47644/TurkishStudies.43923

Received/Geliş: 02 June/Haziran 2020

Accepted/Kabul: 20 September/Eylül 2020

Copyright $($ INTAC LTD, Turkey 
and productivity by supporting employees with more proactive, innovative and unique behaviors. Organizational support can be expressed as making the employees feel that they are making an initiative towards the welfare of the employees in return for their contribution (Büyükgöze and Kavak, 2017: 3). When employees have the perception that they are supported by their organizations, there is a high job satisfaction, an increase in their performance, and a reduction in the turnover rates and intention to quit (Turgut, 2014: 30). One of the concepts that emerged with the provision of organizational support is work engagement. Work engagement can be expressed as reflecting the individual energy to the work while the employees fulfill their duties and responsibilities (Leiter and Bakker, 2010: 2). Employees who are passionate about their work focus deeply on their work and integrate with their work (Yavan, 2016: 280). In other words, employees believe that their general needs are provided within the organization. As a result of this perception, the employee will find his job more meaningful and more valuable, willing to do his job, will feel happy not only in his work life but also in his social life (Başoda, 2017: 94). With the presence of employees who are supported by their managers, who are highly motivated, who have organizational commitment and organizational citizenship behavior, and who have a high level of work engagement, it will be easier for the organization to achieve its goals. Employees who are provided with organizational support will do their job more passionately, more energetically, more connected, and will contribute positively to the performance of the organization. In this context, it is an undeniable fact that the factors such as work engagement and organizational support are effective in increasing the effectiveness and efficiency of organizations. The perception of organizational support provided to the employees, especially within the organization, creates a positive working environment by increasing the employees' work engagement and thus, it would be easier for the organization to reach its goals and objectives.

The aim of this study is to examine the effect of organizational support on the perception of work engagement in white-collar employees in enterprises operating in Antalya. In the research, the questionnaire form was used as a data collection tool, and the questions in the scale were applied face to face to the participants by using the snowball sampling method. The sample of the research is composed of white collar employees in the companies operating in Antalya. The application of the survey to the participants is between June and August 2017. Of the 250 surveys distributed, 227 surveys, which were found to be complete and error-free, were subjected to analysis. Kline, 1994; akt, Özdişçi and Katranc1 (2019: 1567) assume that the number of expressions in the scale should be taken into account in order to determine the sample size. And they had expressed that tenfold of the expressions is appropriate for the sample size. The number of the expressions in this study is 17 . In this context, the sample size is considered to be sufficient because the number of items is more than tenfold of the expressions. The original of the organizational support scale was developed by Eisenberger et al. (1986) and adapted to Turkish by Akalın (2006). The original scale for work engagement was developed by Schaufeli et al. (2002) and adapted to Turkish by Turgut (2011). In the research, the expressions of the participants were taken with the scales arranged as 5-point Likert (1: Absolutely Disagree, ..........., Absolutely Agree). SPSS 22.0 program was used in the analysis of the data. Analyzes were continued by looking at whether the data showed a normal distribution. Parametric tests are used when the data are normally distributed. (Durmus et al., 2013: 65). Tabachnick and Fidell (2014) assume that when the sample size exceeds 200, the data shows a normal distribution when the skewness and kurtosis value is between +1.5 and -1.5 . In the study, it is seen that the skewness and kurtosis values vary between 1.125 and +0.321 . In this case, it can be said that the data show normal distribution.

In order to determine the demographic characteristics of the participants, frequency distribution analysis was used. In order to examine the effect of organizational support between work engagement and its sub-dimensions, first pearson correlation analysis was used, and than multiple regression analysis was used. According to the research findings, $55.1 \%$ of the individuals participating in the research are female and $44.9 \%$ are male; The marital status of $56.8 \%$ is single. $34.3 \%$ age range, $31-36$ and $53.7 \%$ are undergraduate graduates. In the research findings, it was determined that organizational support had an impact on work engagement behavior. In addition, while the dimensions of vigor and dedication have an effect on organizational support, it is determined that organizational support has no effect on the concentration dimension of business concentration. According to the findings obtained, it was found that as the support provided by the organization increases, the employees' passion for their work also increased. For this reason it could be said that the organizational support provided has an important effect on the performance of the employees. In addition, while the dimensions of vigor and dedication have an effect on organizational support, it is determined that organizational support has no effect on the concentration dimension of business

Turkish Studies - Economy, 15(3) 
concentration. In the light of these findings, it can be interpreted that some of the employees have a problematic attitude towards their work.

The research consists of certain constraints. The first of these constraints is that the research is crosssectional. Longitudinal studies need to be compared with the results. Another constraint is that data is obtained from a single sector of employees. The future studies can be suggested by adding different variables (job satisfaction, organizational commitment, organizational cynicism, etc.) in different provinces, in different sectors, in different sizes and samples.

Keywords: Perceived organizational support, organizational support, work engagement.

Öz: Örgütler, değişen çevre koşulları ve küreselleşme sürecinde rekabet avantajı sağlayabilmek için nitelikli insan gücüne ihtiyaç duymaktadırlar. Çalışanların ve örgütlerin performanslarının artmasında örgütsel destek ve işe tutkunluk kavramlarının önemi yadsınamaz bir gerçektir. Örgüt içerisindeki özellikle çalışanlara sağlanan örgütsel destek algısı çalışanın işe tutkunluğunu arttırarak pozitif bir çalışma ortamı oluşturmakta ve böylece sağlanan destek ile örgütün amaç ve hedeflerine ulaşması kolaylaşmaktadır. Bu doğrultuda çalışanlar için önemli bir motivasyon kaynağ 1 olan örgütsel destek algısı, çalışanların işe tutkunluk davranışı eğilimlerini etkileyebilmektedir. Bu çalışmada amaç, Antalya'da faaliyet gösteren işletmelerdeki beyaz yakalı çalışanlarda örgütsel desteğin işe tutkunluk algılları üzerindeki etkisini incelemektir. Araştırmada veri toplama aracı olarak anket formundan yararlanılmıştır. Anket formu, örgütsel destek ve işe tutkunluk ölçeği ile demografik sorulardan (cinsiyet, medeni durum, yaş, eğitim durumu, çalıştığı süre) oluşmaktadır. Veriler, kartopu örnekleme yöntemi ile toplanmıştır. Toplanan veriler, SPSS 22.0 programı kullanılarak analiz edilmiştir. Verilerin analizinde betimleyici istatistikler, Pearson korelasyon, basit doğrusal regresyon ve çoklu regresyon analizlerinden yararlanılmıștır. Araștırma bulguları sonucunda, örgütsel desteğin ișe tutkunluk davranışları üzerinde etkisi olduğu tespit edilmiştir. Ayrıca örgütsel destek üzerinde işe tutkunluğun boyutlarından dinçlik ve adanmışlık boyutları bir etkiye sahipken, işe tutkunluğun yoğunlaşma boyutu üzerinde örgütsel desteğin etkisi olmadığı saptanmıştır. Araştırma sonucuna göre örgütün çalışana sağladığı destek arttıkça çalışanların işlerine olan tutkusunun da arttığı görülmüştür.

Anahtar Kelimeler: Algılanan örgütsel destek, örgütsel destek, işe tutkunluk.

\section{Giriş}

Globalleşen dünyada, işletmelerin varlıklarını sürdürebilmesinde, rekabet üstünlüğü sağlayabilmesinde ve başarılarını arttırabilmesindeki faktörlerden birisi de insan kaynağıdır. Çünkü örgütlerin başarısını yükseltecek temel unsuru örgüt çalışanları oluşturmaktadır. Günümüzde sürdürülebilir rekabet üstünlüğü sağlamanın zorlaşttğı iş dünyasında, örgütler daha proaktif, yenilikçi ve özgün davranışları ile çalışanları destekleyerek etkinlik ve verimliliklerini arttırabilmek için çaba göstermektedirler.

Çalışanın işletmeye yapmış olduğu katkının yöneticisi tarafından fark edilmesi ve değer görülmesi çalışanı mutlu eder. Örgütsel destek, çalışanın yapmış olduğu katkıya karşılık olarak örgüt çalışanlarının refahına yönelik girişimde bulunduğunu çalışanlara hissettirmesi olarak ifade edilebilir (Büyükgöze ve Kavak, 2017: 3). Çalışanlar örgütleri tarafindan desteklendikleri algısına sahip olduklarında yüksek iş tatmini, performanslarında artış, iş gören devir hızlarında ve işten ayrılma niyetlerinde azalmalar görülmektedir (Turgut, 2014: 30). Örgütsel desteğin sağlanmasıyla ortaya çıkan kavramlardan birisi de işe tutkunluktur. İşe tutkunluk, çalışanların görev ve sorumluluklarını yerine getirirlerken bireysel enerjisini işlerine yansıtması olarak ifade edilebilir (Leiter ve Bakker, 2010: 2). İşine tutkuyla bağlanan çalışanlar işlerine derinlemesine odaklanmakta ve yaptığ1 işiyle bütünleşmektedirler (Yavan, 2016: 280). Diğer bir ifade ile işe tutkunluk, çalışanlarının genel ihtiyaçlarının örgüt içerisinde sağlandığına inanmasıdır. $\mathrm{Bu}$ algı sonucunda çalışan işini daha anlamlı ve daha değerli bulacak işini yaparken istekli olacak, sadece çalışma hayatında değil sosyal hayatında da kendisini mutlu hissedecektir (Başoda, 2017: 94). 
Yöneticisi tarafından desteklenen, motivasyonu yüksek olan, örgütsel bağlllık ve örgütsel vatandaşlık davranışı gösteren ve işe tutkunluğu yüksek seviyede olan çalışanların varlığı ile örgütün hedeflediği amaçlara ulaşması kolaylaşacaktır. Örgütsel desteğin sağlandığı çalışanlar işini daha tutkun, daha enerjik, daha bağlı bir şekilde yapacak ve örgütün performansının artmasına olumlu yönde katkı sağlayacaklardır. Bu bağlamda, örgütlerin etkinlik ve verimliliğini arttırmada işe tutkunluk ve örgütsel destek faktörlerinin etkisinin olduğu yadsınamaz bir gerçektir. $\mathrm{Bu}$ çalışmada amaç, Antalya'da faaliyet gösteren işletmelerdeki beyaz yakalı işletme çalışanlarında örgütsel desteğin işe tutkunluk algiları üzerindeki etkisini incelemektir.

Araştırmanın ilk bölümünde, örgütsel destek kavramı, önemi ve literatürde ilişkilendirildiği çalışmalara yer verilmiştir. İkinci bölümde, işe tutkunluk kavramı, boyutları ve literatürde ilişkilendirdiği kavramlar incelenmiştir. Çalışmanın uygulama bölümü olan üçüncü bölümünde araştırma modeli oluşturulmuş, çalışanların örgütsel destek algılarının işe tutkunluk düzeyi algılarına yönelik elde edilen veriler istatistiksel yöntemlerle analiz edilerek araştırma hipotezleri test edilmiştir. Araştırmanın son bölümünde, araştırma bulguları yorumlanmış, literatürde yapılmış olan diğer çalışmalar ile araştırma bulguları tartışılarak araştırma tamamlanmıştır.

\section{Literatür}

\section{Örgütsel Destek}

Destek, genel anlamı ile kişilerin ihtiyaç hissettikleri duygusal, bilişsel ve davranışsal yardımları belirten bir kavramdır (Selçuk, 2003: 2). Algılanan örgütsel destek, 1986 yılında ilk olarak Eisenberger vd., (1986) tarafından geliştirilen çalışmada, çalışanların işletmeye katkıları ve kendilerini iyi hissetmeleri ile ilgili çeşitli durumların, örgütleri tarafından değerli bulunması ve önemsenmesi biçiminde kavramsallaştırılmıştır (Eisenberger vd., 1986: 500; Rhoades ve Eisenberger 2002: 698). Eisenberger vd., (1986)'nin geliştirdiği bu kuram kapsamında algılanan örgütsel desteği geliştiren önemli bir unsurun; çalışanların örgütleri için insanî (humanlike) özellikler sergileme eğilimlerinin olduğu, bu doğrultuda desteklendikleri ifade edilmektedir (Rhoades ve Eisenberger, 2002: 698).

Örgütsel destek, “algllanan örgütsel destek” biçiminde de ifade edilmektedir. Bunun nedeni örgütsel desteğin; kişisel, duygusal ve düşünsel boyutlarda yer almasıdır. Örgütsel destek, soyut nitelikte bir kavram özelliği göstermekte olup çalışanların sahip oldukları tutumların ve kullandıkları stratejilerin sonucunda oluşmaktadır (Köse, 2015: 58). Örgütsel destek, çalışanın örgütü için ortaya koyduğu katkı ile karşılığında örgütün çalışanlarına sağladığ1 desteği, ilgiyi ve bağlılığı çalışanın hissedebilmesi ve algılamasıdır (Demirel, 2013: 224). Bu bağlamda, çalışanların yaratıcı ve yenilikçi önerilerinin, fikirlerinin ve eleştirilerinin göz önünde bulundurulması; iş güvenliklerinin sağlanması, her çalışana adil ve eşit davranılması, onların önemsenmesi örgütsel desteğin temel özellikleri olarak sıralanabilir (Özdevecioğlu, 2003: 116-118 ve Eisenberger vd., 1986: 501). Örgütsel desteğin sağlandığı örgütlerde, çalışanların yöneticileri tarafindan arzu ve beklentilerinin yerine getirileceği varsayımı ile örgütlerine olan duygusal bağlılıkları artacaktır. Bu durumda çalışanlar tüm enerji ve çabalarını örgütün amaç ve hedeflerini gerçekleştirmeye yoğunlaştıracaklardır (Turunç ve Çelik, 2010: 185). Örgütsel desteğe doğrudan etkisi olan önemli bir faktör de örgüt yönetimi ile çalışanlar arasındaki iletişimdir. Yöneticilerin çalışanlarına doğrudan veya dolaylı olarak verdikleri mesajlar, örgütsel destek anlamında etki taşımaktadır. Yöneticilerinden çalışanlara ulaşan ve değerli olduklarına ilişkin pozitif içerik taşıyan mesajlar, övgüler ve çeşitli olumlu geri bildirimler çalışanların örgütsel bağlılıklarını güçlendirecek ve örgüt performansının artmasına katkı sağlayacaktır (Yılmaz ve Görmüş, 2012: 4492; Önderoğlu, 2010: 12).

Literatür incelendiğinde, örgütsel desteğin bazı kavramlar ile ilişkilendirildiği çalışmaların bulunduğu görülmektedir. Örgütsel destek, iş tatmini (Altaş, 2019), duygusal zeka (Demirer ve Polatc1, 2019), örgütsel bağlılık (Lee ve Peccei, 2007; Ngo vd., 2013), örgütlerde güven (Chen vd., 
2005), örgütsel özdeşleşme (Sluss vd., 2008; Battal ve Soyalın, 2020), örgütsel vatandaşlık (Chiang ve Hsieh, 2012; Singh ve Singh, 2010), işten ayrılma niyeti (Rhoades ve Eisenberger, 2002), işe adanmışlık (Meriç vd., 2019; Özdemir vd., 2019), örgütsel adalet (Mert ve Şen, 2019), örgütsel sinizm (Özkara vd., 2019; Kerse ve Karabey 2019; Cole vd., 2006), psikolojik sermaye (Düzgün ve Yeşiltaş, 2019), iş stresi (Serinikli, 2019), meslekten ayrılma niyeti (Seçilmiş vd., 2019), yenilikçi iş davranışı (Sü ve Şıttak, 2019; Janssen, 2000), işe gömülmüşlük (Aykan ve Akgül, 2019), işkoliklik (Çiftçi ve Çankaya, 2019) ve psikolojik sahiplenme (Çıkmaz ve Yeşil, 2020; Pierce vd., 2003) gibi birçok kavramla ilişkilendirilerek inceleme konusu yapılmıştır.

\section{İşe Tutkunluk}

İşe tutkunluk, bazı araştırmalarda "işe angaje olma" (Güneşer, 2007), "işe kapılma" (Öner, 2008), "çalışmaya tutkunluk" (Turgut, 2011), "işe cezbolma" (Dalay, 2007) gibi farkl1 şekillerde ifade edilmiştir (Ardıç ve Polatçı, 2009: 36). İşe tutkunluk kavramından ilk olarak 1990 yılında William A. Kahn tarafindan yapılan çalışmada bahsedilmiştir. Kahn işe tutkunluğu, bireyin işle ve diğer kişilerle bağlantısını sağlayan; fiziksel, bilişsel, duygusal ve davranışsal olarak kendilerini sahip oldukları işe adamaları şeklinde ifade etmiştir (Kahn, 1990: 694). İşe tutkunluk, kurumların başarılı olabilmeleri için istihdam ilişkilerinin temelinde var olan ve kurumların sürdürülebilir rekabet gücü elde etmesinde kritik önem taşıyan bir kavram olarak kabul edilmektedir (Armstrong, 2008: 141).

Schaufeli ve Bakker işe tutkunluk kavramını üç alt boyut altında incelemişlerdir. Bunlar; dinçlik (vigor), adanmışlık (dedication) ve yoğunlaşma (obserbed)'dır (Schaufeli vd., Bakker, 2002: 749). İşe tutkunluk boyutu olan dinçlik; bireylerin kendilerini fiziksel anlamda enerjik hissetmesi, duygusal anlamda güçlü ve ilham verici olması, zihinsel olarak dayanıklı olması, yaşadığı zorluklarla mücadele edebilme ve karşı durabilme gibi özelliklere sahip olmasıdır. Yüksek enerji düzeyine sahip olan çalışanlar işe ve çalıştığı örgüte daha fazla katkı sağlayabilmek için istekli olmaktadırlar (Turgut, 2011: 156). Bireyler kendilerini dinç hissettikleri zaman zorluklar karşısında sabırlı ve güçlü bir şekilde işin gerekliliklerini yerine getirmeye çalışmaktadırlar (Çalışkan, 2014: 370). Adanmışlık boyutu, çalışanın işine oldukça bağlı olması ve yüksek düzeyde katılım göstermesini ifade etmektedir. Adanmışlık yaşayan bireyler; mücadele edebilmeye değer, işlerine kıymet veren ve istekli, hizmet ettiği işin amacının önemli olduğunu düşünmektedirler. Bu kişiler işlerini büyük bir istekle yaptıkları için işleri onlar için bir övünç kaynağıdır (Turgut, 2011: 156). Yoğunlaşma boyutu ise, bireyin işinin başındayken zamanın nasıl geçtiğini anlamayacak kadar işlerine odaklanmış ve işini yaparken diğer tüm faktörlerden kendisini izole etmesi olarak ifade edilebilir (Schaufeli vd., 2002: 73). İşinden kendini alıkoyamaz hale gelen bireyler işlerine yoğunlaştıklarından kendileri için işlerinin vazgeçilmez olduğunu düşünmektedirler (Turgut, 2013: 2).

İşe tutkunluğu etkileyen bazı faktörler bulunmakta olup bu faktörler bireysel ve örgütsel olmak üzere ikiye ayrılmaktadır. Bireyin kendisini tanıması, kişisel gelişimine önem vermesi, stres ve zaman yönetimini iyi yapabilmesi, yeterli düzeyde bilgi ve donanıma sahip olması gibi özellikler bireysel faktörler arasında yer alırken; bireylerin iş yükü kontrollerinin yapılması, oryantasyon eğitimlerinin sağlanabilmesi, grup halindeki çalışmalarının desteklenmesi gibi özellikler ise örgütsel faktörler arasında yer almaktadır (Özer vd., 2015: 263). Hem çalışan hem de örgüt için işe tutkunluğun olumlu girdi ve çıktıları bulunmaktadır (Bakker vd., 2011: 4-28). İse tutkun olan çalışanların diğer çalışanlara göre fiziksel ve psikolojik sağlık durumlarının daha iyi olduğu dikkat çekmektedir (Sonnentag, 2003: 520). İşe tutkunluğu yüksek olan çalışanların, proaktif davranışlar sergilediği, psikolojik sermayesinin, iş tatmininin ve motivasyonunun daha yüksek olduğu, kurumlarına olan bağlılıklarının daha fazla olduğu, işten ayrılma niyetlerinde ve iş gören devir hızlarında azalmalar olduğu gözlemlenmektedir (Schaufeli ve Bakker, 2004: 4).

Literatür incelendiğinde, işe tutkunluğun bazı kavramlar ile ilişkilendirildiği çalışmaların bulunduğu görülmektedir. İşe tutkunluk, tükenmişlik (Schaufeli vd., 2002), izlenim yönetimi 
davranış1 (Bektaş ve Karagöz, 2018), yönetici desteği (Turgut, 2011), işkoliklik (Schaufeli vd., 2008), lider-üye etkileşimi (Uzunbacak vd., 2018), örgütsel güven (Özdemir vd., 2019), örgütsel bağl11ık (Cho vd., 2006), proaktif kişilik (Bakker vd., 2012), örgütsel vatandaşlık (Örücü ve Uçku, 2019), işe gömülmüşlük (Prathiba, 2016) gibi birçok kavramla ilişkilendirilerek inceleme konusu yapılmıştır.

\section{Örgütsel Destek ve İşe Tutkunluk Arasındaki İlişki}

Örgütsel destek olumlu duyguları içeren, çalışanların örgüte olan katkılarının farkında olduğu, çalışanlarının huzuruna ve mutluluğuna değer verdiği, çalışanın örgüte ait olduğunu hissetmesi gibi bazı sosyo-psikolojik ihtiyaçlarını karşılamaya yönelik bir kavramdır (Özdemir, 2010: 241). Örgütsel destek algısı yüksek seviyede olan çalışanlar örgüte olan katkılarını arttırmak için yüksek performans göstermektedirler (Stamper ve Johlke, 2003: 571). İşe tutkunluk kavram1 ise, çalışanın işine olan ilgisi ve katılımıdır. İşe bağlılığı yüksek olan çalışanlar işiyle kendini bütünleştirirler. Diğer çalışanlara göre daha fazla çalışma eğilimi göstererek, örgütlerin amaç ve hedeflerine ulaşmasında daha fazla katkı sağlarlar (Roberts ve Davenport, 2002: 21).

Örgütsel destek kuramının kökeni, Blau (1964) tarafından geliştirilen sosyal mübadele/değişim kuramına dayanmaktadır (Eisenberger vd., 1997: 812). Çalışan öncelikle örgütün kendisine sağlamış olduğu maddi ve manevi ödüllendirmeler ile ilgili kendisi bir değerlendirme yapmaktadır (Saks, 2006: 602-603). Bu teoriye göre, çalışanlar karşılıklı ilişkilerinde örgütlerinin kendilerine sağladıkları desteği doğru algılamaları sonucunda sahip oldukları görev ve sorumlulukları daha iyi yerine getirmeye çalışacaklardır. Bunun sonucunda çalışanın işini daha iyi yaptığı, işe devamsızlıklarda azalmaların olduğu, örgütsel vatandaşlık davranışı gösterdikleri, buna karşılık olarak artan iş doyumu ile örgütte sosyal değişimin karşılıklı olarak olumlu bir atmosfer oluşturduğu söylenebilir (Eisenberger vd., 2001: 42-43). Bu bağlamda örgüt, çalışanlarının beklentilerini sağlıyor ve bunu çalışanlarına hissettiriyorsa, çalışanlar örgütün amaç ve hedeflerini yerine getirebilmek için daha fazla çaba gösterecekler ve işlerini daha tutkuyla yapmaya başlayacaklardır (Turunç ve Çelik, 2010: 185).

\section{Çalışmanın Hipotezleri}

Yukarıda verilen bilgilerin 1şığında algılanan örgütsel destek ile işe tutkunluk arasında bir ilişki olabileceği sosyal mübadele/değişim kuramıyla desteklenmiş ve algılanan örgütsel desteğin işe tutkunluğu etkileyebileceği varsayılarak bu çalışmada aşağıdaki hipotezler önerilmiştir:

$\mathrm{H}_{1:}$ Örgütsel desteğin işe tutkunluk üzerine bir etkisi vardır.

$\mathrm{H}_{1 \mathrm{a}}$ Örgütsel desteğin dinçlik boyutu üzerine bir etkisi vardır.

$\mathrm{H}_{1 \mathrm{~b}}$ Örgütsel desteğin adanmışlık boyutu üzerine bir etkisi vardır

$\mathrm{H}_{1 \mathrm{c}}$ Örgütsel desteğin yoğunlaşma boyutu üzerine bir etkisi vardır.

\section{Yöntem}

\section{Araştırmanın Amacı ve Modeli}

Bu çalışmada amaç, Antalya'da faaliyet gösteren işletmelerdeki beyaz yakalı çalışanlarda örgütsel desteğin işe tutkunluk algıları üzerindeki etkisini incelemektir. Bu amaç doğrultusunda aşağıdaki model oluşturulmuştur.

\section{Araştırma Modeli}

Bu amaçla oluşturulan araştırma modeli Şekil 1'de gösterilmiştir. 


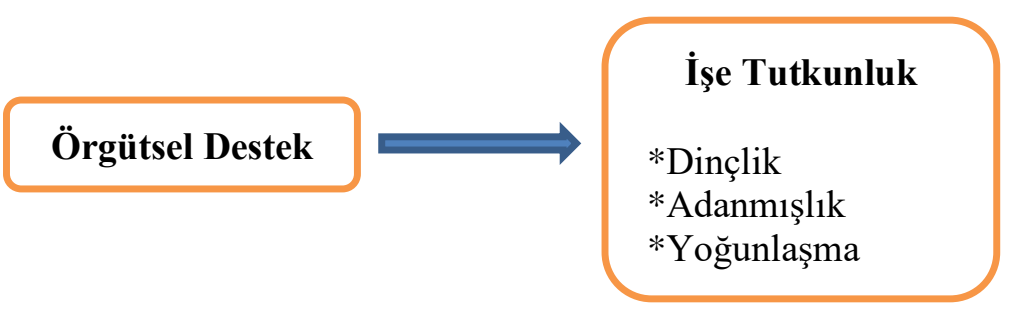

\section{Araştırmanın Örneklemi}

Şekil: 1. Araştırma Modeli

Araştırmada veri toplama aracı olarak anket formundan faydalanılmış olup kartopu örnekleme yöntemi kullanılarak ölçekteki sorular katılımcılara yüz yüze uygulanmıştır. Araştırmanın örneklemini, Antalya'da faaliyet göstermekte olan işletmelerdeki beyaz yakalı çalışanlar oluşturmaktadır. Anketin katılımcılara uygulanması Haziran-Ağustos 2017 tarihleri arasındadır. Dağıtılan 250 anketten eksiksiz ve hatasız olduğu tespit edilen 227 anket analize tabi tutulmuştur (Kline, 1994; akt: Özdiş̧̧i ve Katranc1, 2019: 1567), örneklem büyüklüğünü tespit etmek amacıyla ölçekteki ifadelerin sayısının dikkate alınması gerektiğini ve ifade sayısının 10 katı bir örneklemin uygun olduğunu varsaymaktadır. Bu çalışmadaki ifade sayısı 17'dir. Bu bağlamda örneklem büyüklüğü madde sayısının 10 katı olması ve iyi olarak değerlendirilmesi sebebiyle örneklemin yeterli olduğu düşünülmektedir.

\section{Ölçüm Araçları}

Antalya'da faaliyet gösteren işletmelerdeki beyaz yakalı çalışanlarda örgütsel desteğin işe tutkunluk algıları üzerindeki etkisini incelemek amacıyla örgütsel destek ve işe tutkunluk ölçeklerinden faydalanılmıştır.

\section{Örgütsel Destek Ölçeği}

Örgütsel destek ölçeğinin orijinali Eisenberger vd., (1986), tarafından geliştirilmiş ve Akalın (2006) tarafindan Türkçeye uyarlanmıştır. "Çalıştığım kurum yaptı̆̆ım dürüst bir hatayı bağışlayacaktır" ve "Çalıştığım kurum firsat bulursa beni istismar eder", şeklinde sorular ölçekte yer alan sorulara örnektir ve bu örnek sorular aynı zamanda ters kodlanan sorulardır. Ölçekte örgütsel destek ölçeği toplam sekiz ifade olup tek boyut altında toplanmıştır.

\section{İşe Tutkunluk Ölçeği}

İşe tutkunluk ölçeğinin orijinali Schaufeli vd., (2002), tarafından geliştirilmiş ve Turgut (2011) tarafindan Türkçeye uyarlanmıştır. "Yoğun çalıştığım zamanlarda kendimi mutlu hissederim." ve "Işsimde kendimi güçlü ve dinç hissederim." şeklinde sorular ölçekte yer alan sorulara örnektir. Çalışmaya tutkunluk ölçeği toplam dokuz ifadeden oluşmakta olup üç alt boyut altında dinçlik, adanmışlık ve yoğunlaşma olarak üçer ifade ile temsil edilmektedir.

Araştırmada, 5'li Likert (1: Kesinlikle Katılmıyorum,...........,Kesinlikle Katılıyorum) olarak düzenlenen ölçeklerdeki ifadelerle katılımcıların görüşleri alınmıştır.

\section{Verilerin Analizi}

Verilerin analizinde SPSS 22.0 programından yararlanılmıştır. Verilerin normal dăğılım gösterip göstermediğine ilişkin analiz yapılmıştır. Parametrik testler verilerin normal dağılım göstermesi durumunda kullanılmaktadır (Durmuş vd., 2013: 65). Tabachnick ve Fidell (2014), örneklem büyüklüğünün 200'ü geçtiği durumlarda çarpıklık ve basıklık değeri +1.5 ve -1.5 arasında olduğunda verilerin normal dağılım gösterdiğini varsaymaktadırlar. Araștırmada çarpıklık ve basıklık değerlerinin -1.125 ile +0.321 arasında değiştiği görülmektedir. Bu durumda verilerin normal dağılım gösterdiği söylenebilir. Veriler normal dağılım gösterdiği için de parametrik testler 
tercih edilmiştir. Katılımcıların demografik özelliklerini tespit etmek amacıyla frekans dağılımı analizinden, örgütsel desteğin işe tutkunluk ve alt boyutları arasındaki etkisini incelemek amacıyla ilk olarak Pearson korelasyon analizi ikinci olarak da basit doğrusal regresyon ve çoklu regresyon analizinden yararlanılmıştır.

\section{Bulgular} bakılmıştır.

Bu bölümde örgütsel destek ve işe tutkunluk değişkenlerinin geçerlik ve güvenilirliklerine

\section{Ölçeğin Geçerlik ve Güvenilirliği}

Katılımcıların ankete yönelik vermiş oldukları yanıtların faktör analizi için uygunluğu test edilmiştir. Örneklem büyüklüğü sıfir ile bir arasında değişkenlik gösterdiğinde ve KMO değeri bire yakın olduğunda örneklemin faktör analizi için uygun olduğu varsayılmaktadır (Kalayc1, 2006). Faktör analizi öncesi ölçeğin sınamaya uygunluğunu ölçebilmek için gerçekleşen Bartlet'in küresellik testi ve KMO (Kaiser-Meyer-Olkin) testinde örgütsel destek ölçeği KMO değeri .82 ve işe tutkunluk ölçeği KMO değeri .75 'dir. Bartlet'in küresellik testi 0,000 olup anlamlıdır. KMO değeri .60 'dan büyük olduğu için örneklem büyüklüğü yeterlidir ve Bartlet'in küresellik testi sonucu $\mathrm{p}<0.05$ olduğu için veriler birbiri ile ilişkilidir. Bu bulgular açıklayıcı faktör analizi (AFA) sonuçlarının kabul edilebilir olduğunu destekler niteliktedir (Lewis ve Beck, 1994).

Tablo 1: Güvenilirlik ve Geçerlilik

\begin{tabular}{cccccc}
\hline Değişkenler & \multicolumn{1}{c}{$\begin{array}{c}\text { Güvenilirlik } \\
\text { Düzeyi }\end{array}$} & KMO & $\overline{\mathbf{x}}$ & Ss \\
\hline 1. & Örgütsel Destek & .70 & .75 & 3,22 & .51 \\
\hline 2. & İşe Tutkunluk & .80 & .82 & 3,69 & .73 \\
2.1. Dinçlik & .60 & & 3,63 & .90 \\
2.2. Adanmişlık & .71 & & 3,89 & .79 \\
2.3.Yoğunlaşma & .67 & & 3,49 & .94 \\
\hline
\end{tabular}

Soru formunda yer alan ifadelerin güvenilirliklerine bakılmıştır. Araştırmacılardan bir kısmının Cronbach Alfa katsayısı değeri ile ilgili (Büyüköztürk, 2004), .70'den büyük olması gerektiğini savunurken, sosyal bilimler alanında bir kısım araştırmacılar ise (Kalaycı, 2006) .60 'dan büyük değerlerin rakamsal değer öngörüsü ile güvenilirlik derecesi bakımından yüksek kabul edilen değerler olarak yorumlanmıştır. Araştırmada kullanılan ölçekler için gerçekleştirilen güvenilirlik analizi sonucu örgütsel destek ölçeğine ait Cronbach Alfa katsayısı .80, işe tutkunluk ölçeğine ait Cronbach Alpha değeri .70 olduğu sonucuna ulaşılmıştır. Analizlerden elde edilmiş olan sonuçların yukarıda belirtilmiş olan değerlerin üstünde çıkmış olmasından dolayı ölçeklerin güvenilir olduğu yorumu yapılabilir.

\section{Tanımlayıcı İstatistikler ve Değişkenler Arası İlişkiler}

Tanımlayıcı istatistikler kısmında; katılımcılara ait demografik özelliklere ve diğer istatistiklere ilişkin bilgilere yer verilmiştir. 


\begin{tabular}{|c|c|c|c|}
\hline \multicolumn{4}{|c|}{ Tablo 2: Demografik Özellikler } \\
\hline & & $\mathbf{n}$ & $\%$ \\
\hline \multirow{2}{*}{ Cinsiyet } & Kadın & 102 & 44,9 \\
\hline & Erkek & 125 & 55,1 \\
\hline \multirow{2}{*}{ Medeni Durum } & Evli & 129 & 56,8 \\
\hline & Bekâr & 98 & 43,2 \\
\hline \multirow{5}{*}{ Yaş } & 30 yaş ve altı & 30 & 13,2 \\
\hline & $31-36$ & 78 & 34,3 \\
\hline & $37-43$ & 44 & 19,3 \\
\hline & $44-49$ & 31 & 13,7 \\
\hline & 50 ve üzeri & 44 & 19,3 \\
\hline \multirow{3}{*}{ Eğitim Durum } & Ön Lisans & 65 & 28,6 \\
\hline & Lisans & 122 & 53,7 \\
\hline & Lisans Üstü & 40 & 17,7 \\
\hline \multirow{5}{*}{ Çalışma Süresi } & 1 yıldan az & 44 & 19,4 \\
\hline & $1-5$ y1l aras1 & 81 & 35,7 \\
\hline & 6-10 y1l arası & 48 & 21,1 \\
\hline & $11-15$ yıl ve üzeri & 35 & 15,4 \\
\hline & 16 yil ve üzeri & 19 & 8,4 \\
\hline
\end{tabular}

Tablo 2 incelendiğinde; katılımcıların demografik özellikleri konusunda bilgi verilmektedir. Araştırmaya katılan bireylerin \%55,1'i kadın, \%44,9'u erkek iken; \%56,8'inin medeni durumu bekârdır. \%34,3 yaş aralığ $131-36, \% 53,7$ 'si lisans ve \%35,7'sinin çalışma süresi 15 yıl arasindadır.

Tablo 3: Değişkenler Arası İlişkiler

\begin{tabular}{lcccc}
\hline Değişkenler & $\mathbf{1}$ & $\mathbf{2}$ & $\mathbf{3}$ & $\mathbf{4}$ \\
\hline İşe Tutkunluk & 1 & & & \\
Dinçlik & $.865^{* *}$ & 1 & & \\
Adanmışlı & $.794^{* *}$ & $.572^{* *}$ & 1 & \\
Yoğunlaşma & $.852^{* *}$ & $.604^{* *}$ & $.482^{* *}$ & 1 \\
Örgütsel Destek & $.411^{* *}$ & $.365^{* *}$ & $.367^{* *}$ & $.280^{* *}$ \\
\hline$* * \mathrm{p}<0,01$ & & &
\end{tabular}

Araştırmanın değişkenleri arasındaki ilişkileri belirlemek üzere Pearson Korelasyon analizi yapılmıştır. Tablo 3 ’te görüldüğü üzere örgütsel destek işe tutkunluğun dinçlik $(r=.865, p<0,01)$, adanmışlık $(\mathrm{r}=.794, \mathrm{p}<0,01)$ ve yoğunlaşma $(\mathrm{r}=.852, \mathrm{p}<0,01)$ boyutları arasında yüksek düzeyde pozitif yönde anlamlı ilişki içerisinde olduğu tespit edilmiştir. Bununla birlikte, örgütsel destek ile işe tutkunluk arasında pozitif yönlü anlamlı $(\mathrm{r}=.411, \mathrm{p}<0,01)$ ilişki bulunmaktadır.

\section{Hipotez Testlerine İlişkin Bulgular}

Araştırma hipotezlerini test etmek için regresyon analizinden faydalanılmıştır. Regresyon analizi, iki ya da daha fazla değişkenin birinin bağımlı diğerlerinin bağımsız değişen olmasıdır (Büyüköztürk, 2004: 91). Araştırma hipotezlerini test etmeye başlamadan önce Durbin Watson (DW) katsayısı ile otokorelasyonun varlı̆̆ına bakılmıştır. Bu değer 1,5-2,5 arasında olduğunda otokorelasyonun var olduğu varsayılmaktadır. Araştırma bulgusunda Durbin Watson katsayılarının 1,724 ile 2,390 arasında değerler aldığ varsayımının gerçekleştirildiğinin göstergesidir. Varsayımlardan bir diğeri incelendiğinde, Tolerans değerinin .20 'den büyük, VIF değerinin ise 10 'dan küçük olmasının kabul edilebilir seviyede olduğunun göstergesidir (Field, 2009: 293). Bu bulgular doğrultusunda araştırmada çoklu bağlant1 sorunu olmadığı sonucuna ulaşılmıştır. 
Tablo 4: Örgütsel Desteğin İşe Tutkunluk Üzerine Etkisi

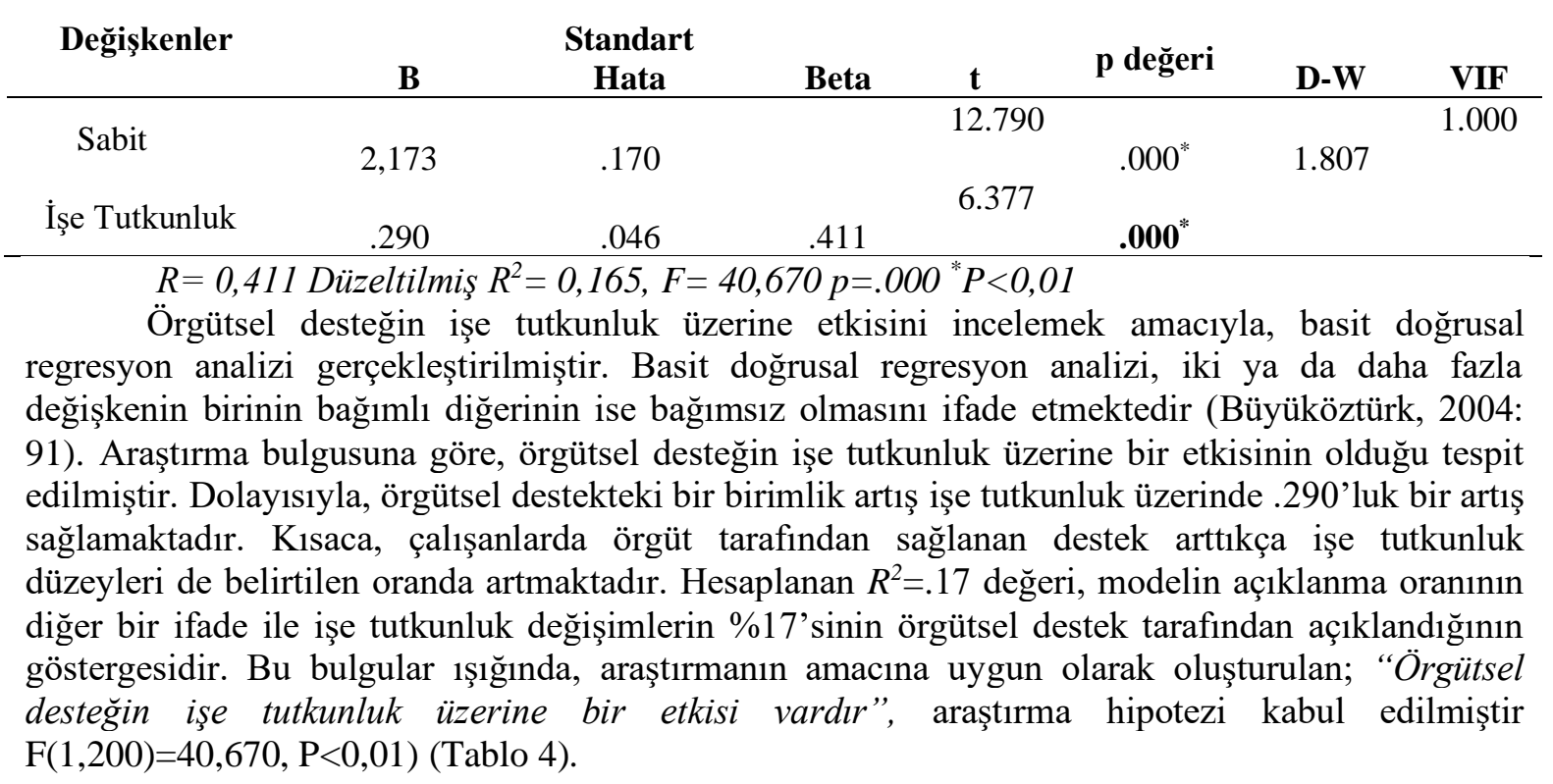

Tablo 5: Alg1lanan Örgütsel Desteğin İşe Tutkunluk ve Boyutlanı Üzerine Etkisi

\begin{tabular}{|c|c|c|c|c|c|c|c|}
\hline Değişkenler & & Standart & & & p değeri & & \\
\hline & B & Hata & Beta & $\mathbf{t}$ & & D-W & VIF \\
\hline \multirow{2}{*}{ Sabit } & & & & 12.434 & & & \multirow{3}{*}{1.649} \\
\hline & & .171 & & & .000 & 1.000 & \\
\hline Dinçlik & .019 & .048 & .033 & \multirow{2}{*}{$\begin{array}{r}0.400 \\
4.851\end{array}$} & $.017^{* *}$ & & \\
\hline Adanmışlık & .228 & .047 & .370 & & $.003^{* * *}$ & & 1.450 \\
\hline Yoğunlaşma & .059 & .045 & .107 & 1.309 & $0,192^{* *}$ & & 1.652 \\
\hline
\end{tabular}

Örgütsel desteğin, işe tutkunluk ve boyutları üzerindeki etkisini incelemek amacıyla, çoklu regresyon analizinden faydalanılmıştır. Çoklu regresyon analizi, bir bağımlı değişken ile birden fazla bağımsız değişken ile yapılmış olan analiz olarak ifade edilmektedir (Büyüköztürk, 2004: 98). Yukarıdaki modelde Durbin Watson değerinin 1,5-2,5 arasında olması ve VIF değerinin 10'dan küçük olması otokorelasyonun olmadığının göstergesidir. $\mathrm{Bu}$ bulgu ile çoklu regresyon analizindeki varsayımların gerçekleştirildiğini söylemek mümkündür. Araştırma sonucunda birinci olarak dinçlik boyutunun örgütsel destek üzerinde bir etkiye sahip olduğu tespit edilmiştir $(t=0,400$ $\mathrm{p}=0,017, \mathrm{p}<0,01)$. Bu bulgu dinçlik boyutundaki bir birimlik artış örgütsel destek üzerinde .033'lük bir artış sağlamaktadır. Kısaca çalışanlarda örgütsel destek artıkça buna paralel olarak çalışanın dinçlik düzeylerinde de artışlar gözlemlenecektir. İkinci olarak, adanmışlık boyutu örgütsel destek üzerinde bir etkiye sahip olduğu tespit edilmiştir $\left(\mathrm{t}=4,851 \mathrm{p}=003^{*}, \mathrm{p}<0,01\right)$, Bu bulgu adanmışl1k boyutundaki bir birimlik artışın örgütsel destek üzerinde .370'lik bir artış sağladığını ortaya koymaktadır. Kısaca çalışana sağlanan örgütsel destek arttıkça çalışanın işe olan adanmışlığında da artmalar olacaktır. Ve üçüncü olarak oluşturulan modelde, yoğunlaşma boyutunun örgütsel destek üzerinde bir etkiye sahip olmadığ1 tespit edilmiştir $(\mathrm{t}=1,309, \mathrm{p}=0,192, \mathrm{p}<0,01)$. Araştırmanın amacına uygun olarak geliştirilen; "Örgütsel desteğin dinçlik boyutu üzerine bir etkisi vardır.", "Örgütsel desteğin adanmışlık boyutu üzerine bir etkisi vardır.", hipotezleri kabul edilmiş olup 
"Örgütsel desteğin yoğunlaşma boyutu üzerine bir etkisi vardır." araştırma hipotezi ise red edilmiştir $\mathrm{F}(3,198)=16,986, \mathrm{P}<0,01)$ (Tablo 5).

\section{Hipotez Testleri Sonuç Bulguları}

Hipotezleri test etmek amaciyla, bağımsız örneklem $t$ testi ve tek yönlü varyans analizi (ANOVA) testi kullanılmıştır. Araştırmada demografik değişkenlere yönelik temel ve alt hipotezler oluşturulmuştur. Bu yapılan analizler sonucunda Tablo 6'da hipotezlerin red ya da kabulüne ilişkin bulgulara yer verilmiştir.

Tablo 6: Hipotez Testleri Sonuç Tablosu

\begin{tabular}{lccc}
\hline \multicolumn{1}{c}{ Hipotezler } & p değeri & t değeri \\
\hline $\mathrm{H}_{1:}$ Algılanan örgütsel desteğin işe tutkunluk üzerine bir etkisi vardır. & .000 & 2.790 & Kabul \\
$\mathrm{H}_{1 \mathrm{a}: \text { Algılanan örgütsel desteğin dinçlik boyutu üzerine bir etkisi }}$ & .017 & 0.400 & Kabul \\
vardır. & & & \\
$\mathrm{H}_{1 \mathrm{~b}}$ Algılanan örgütsel desteğin adanmışlık boyutu üzerine bir etkisi & .003 & .851 & Kabul \\
vardır \\
$\begin{array}{l}\mathrm{H}_{1 \mathrm{c}:} \text { Algılanan örgütsel desteğin yoğunlaşma boyutu üzerine bir etkisi } \\
\text { vardır. }\end{array}$ & .192 & .309 & Red \\
\hline
\end{tabular}

\section{Sonuç ve Tartışma}

Günümüzde hem hizmet hem de üretim sektörlerinde rekabetin artması ile birlikte örgütler kaynaklarını nasıl daha verimli kullanabildiklerini sorgulamaya başlamışlardır. Örgütlerin verimliliğini arttırabilmek için sahip olduğu kaynakların en önemlisi ve değerlisi çalışanlarıdır. Sürdürülebilir rekabet üstünlüğü sağlayabilmek, karlılığı arttırabilmek için örgütler çalışanlarına destek sağlamaktadırlar. Sağlanan bu destek ile çalışanın örgüte olan bağl1lığında, örgütsel vatandaşlık sergilemesinde, işten ayrılma niyetlerinde farklılaşmalar meydana gelmeye başlamaktadır. Bunların yanında örgütün çalışanlarına sağlamış olduğu destek çalışanın işine olan tutkunluklarında da farklılaşmaları beraberinde getirmektedir. Bu bağlamda örgütün karlılığını ve verimliliğini arttırmasında örgütün çalışanına sağlamış olduğu desteğin önem arz ettiğini söylemek mümkündür.

Bu çalışmada amaç, Antalya'da faaliyet gösteren işletmelerdeki, beyaz yakalı çalışanlarda örgütsel desteğin çalışanın işe tutkunluk algıları üzerindeki etkisini incelemektir. Araştırma sonucuna göre, algılanan örgütsel desteğin işe tutkunluk üzerinde etkisi olduğu tespit edilmiştir. Ayrıca örgütsel destek üzerinde işe tutkunluğun boyutlarından dinçlik ve adanmışlık boyutları bir etkiye sahipken işe tutkunluğun yoğunlaşma boyutu üzerinde örgütsel desteğin etkisi olmadığı saptanmıştır.

Elde edilen bulgulara göre, örgütün çalışanına sağladığ 1 destek arttıkça, çalışanın işine olan tutkunluğunun da arttı̆̆ ve sağlanan örgütsel desteğin çalışanların performansında önemli bir etkiye sahip olduğu yorumu yapılabilir. Ayrıca örgütsel destek, işe tutkunluğun alt boyutlarından adanmışlık ve dinçlik boyutu üzerinde bir etkiye sahipken, yoğunlaşma boyutu üzerinde bir etkiye sahip olmadığı saptanmıştır. Bu bulgular ışığında, örgütsel desteğin her ne kadar adanmışlık ve dinçlik boyutu üzerinde bir etkisi olduğu ve çalışanların işlerine tutkun olduğu addedilse de, yoğunlaşma boyutu üzerinde etkinin saptanamaması çalışanların bir kısmının çalışmaya yönelik tutumlarının ve kendilerini işe vermelerinde sıkıntılı yaşadı $\breve{g}_{1}$ yorumu yapılabilir.

Örgütsel destek ile ișe tutkunluk arasında ilișki olduğu ve bu kavramların birbirini etkilediği bazı çalışmalar ile de desteklenmiştir. Güvenç (2012), çalışmaya tutkunlukla işe verilen destek arasındaki ilişkiyi incelemiştir. Araştırma bulgusuna göre, işe yönelik destek ile işe tutkunluk arasında kısmi bir ilişki olduğu sonucuna ulaşmıştır. Caesens ve Stinglhamber (2014), işletme çalışanları üzerinde yapmış olduğu araştırmasında örgütsel destek ile işe adanmışlık 
arasında bir ilişki olduğunu tespit etmiştir. Dai ve Quin (2016), Çin'de gerçekleştirmiş olduğu çalışmasında örgütsel destek ve işe adanmışlık arasında pozitif yönde bir ilişki olduğu sonucuna ulaşmışlardır. İnce (2016), bir konfeksiyon firması üzerinde yapmış olduğu araştırma sonucunda, örgütsel destek ile işe tutkunluk değişkenleri arasında pozitif yönlü bir ilişki olduğunu tespit etmiştir. Murthy (2017), örgütsel destek ve işe tutkunluk arasında bir ilişki olduğu sonucuna ulaşmıştır. Örücü ve Uçku (2019), örgütsel destek ve işe tutkunluk arasında bir ilişki olduğunu tespit etmişlerdir. Meriç vd., (2019), kamuda görev yapan öğretmenler üzerinde yapmış olduğu araştırmada örgütsel destek ve işe tutkunluk arasında bir ilişki olduğu bulgusuna ulaşmışlardır. Özdemir vd., (2019), öğretim elemanları üzerinde incelemiş olduğu çalışmada değişkenler arasında bir ilişki olduğunu tespit etmişlerdir. Bu bulgular bu araştırmanın sonuçlarını destekler niteliktedir.

Araştırma belirli kısıtlardan oluşmaktadır. $\mathrm{Bu}$ kısıtlardan ilki, araştırmanın kesitsel olmasıdır. Boylamsal araştırmaların neticeleri ile karşılaştırılması gerekmektedir. Bir diğer kısıt ise, verilerin tek bir sektör çalışanlardan elde edilmiş olmasıdır. İleride yapılacak olan çalışmalar farklı değişkenler eklenerek (iş tatmini, örgütsel bağl1lık, örgütsel sinizm vs.) farklı illerde, farklı sektörlerde, farklı büyüklükte örneklem ve evrende yapılması önerilebilir.

\section{Kaynakça}

Akalın, Ç. (2006). Duygusal örgütsel bağglllk gelişiminde çalışanların algıladığı örgütsel destek ve ara bir değişken olarak örgüt temelli öz-saygl. Yüksek Lisans Tezi, Hacettepe Üniversitesi, Sosyal Bilimler Enstitüsü.

Altaş, S. S. (2019). Çalışanların Algıladıkları örgütsel desteğin duygusal bağlılık ve iş tatmini üzerindeki etkisi, Uluslararası Sosyal Araştırmalar Dergisi, 12(64). http://dx.doi.org/10.17719/jisr.2019.3403

Ardıç, K. ve Polatçı, S. (2009). Tükenmişlik sendromu ve madalyonun öbür yüzü: işle bütünleşme, Erciyes Üniversitesi İktisadi ve İdari Bilimler Fakültesi Dergisi, 32, 21-46.

Armstrong, M. (2008), Strategic Human Resource Management, 4th Edition, Kogan Page Limited.

Aykan, E. ve Akgül, H. (2019). Örgütsel desteğin işe gömülmüşlük davranışları üzerindeki etkisinde işgören avukatlığının aracılık rolü: kayseri lojistik sektörü çalışanları üzerine bir araştırma, Manas Sosyal Araştırmalar Dergisi, 8(3), 2714-2733. https://doi.org/10.33206/mjss.465906

Bakker, A. B., Albrecht, S. L. and Leiter, M. P. (2011). Key questions regarding work engagement, European Journal of Work and Organizational Psychology, 20(1), 4-28. https://doi.org/10.1080/1359432X.2010.485352

Bakker, A. B., Tims, M. and Derks, D. (2012). Proactive personality and job performance: the role of job crafting and work engagement. Human Relations, 65(10), 1359-1378. https://doi.org/10.1177/0018726712453471

Başoda, A. (2017). İşe tutkunluk: kavramsal açıdan bir inceleme, Uluslararası Tarih ve Sosyal Araştırmalar Dergisi, 17, 71-98.

Battal, F. ve Soyalın, M. (2020). Algılanan örgütsel desteğin örgütsel özdeşleşmeye etkisi: psikolojik güvenliğin aracı rolü. Atatürk Üniversitesi Sosyal Bilimler Enstitüsü Dergisi, 24 (1), 161-173.

Bektaş, M. ve Karagöz, Ş. (2018). İzlenim yönetimi davranışının işe tutkunluğa etkisinde sosyal görünüş kaygısının aracılık rolü, Sosyal Araştırmalar ve Davranış Bilimleri Dergisi, 4(6), 275-299.

Turkish Studies - Economy, 15(3) 
Blau, P. M. (1964). Exchange and power in social life, Wiley.

Büyükgöze, H. ve Kavak, Y. (2017). Algilanan örgütsel destek ve pozitif psikolojik sermaye ilişkisi: lise öğretmenleri örnekleminde bir inceleme. Kuram ve Uygulamada Eğitim Yönetimi, 23(1), 1-32. https://doi.org/10.14527/kuey.2017.001

Büyüköztürk, Ş. (2004). Sosyal Bilimleri İçin Veri Analizi El Kitabı, İstatistik, Araştırma Deseni SPSS Uygulamalart ve Yorum, Pegem Akademi.

Caesens, G. and Stinglhamber, F. (2014). The relationship between perceived organizational support and work engagement: the role of self-efficacy and its outcomes, Revue Européenne De Psychologie Appliquée, 64(5), 259-267. https://doi.org/10.1016/j.erap.2014.08.002

Chen, Z. X. Aryee, S. and Lee, C. (2005). Test of a mediation model of perceived organizational support, Journal of Vocational Behavior, 66, 457-470. https://doi.org/10.1016/j.jvb.2004.01.001

Chiang, C. F. and Hsieh, T. S. (2012). The mpacts of perceived organizational support and psychological empowerment on job performance: the mediating effects of organizational citizenship Behavior, International Journal of Hospitality Management, (31), 180-190. https://doi.org/10.1016/j.jijm.2011.04.011

Cho, J., Laschinger, H. S. and Wong, C. (2006). Workplace empowerment, work engagement and organizational commitment of new graduate nurses, Nursing Leadership-Academy of Canadian Executive Nurses, 19(3), 43-60. https://doi.org/10.12927/cjnl.2006.18368

Cindiloğlu Demirer, M. ve Polatcı, S. (2019). Örgütsel-sosyal destek ile duygusal zekânın iş ve yaşam tatmini üzerine etkisi. Çankırı Karatekin Üniversitesi İ̈BF Dergisi, 9 (2), 381-399. https://doi.org/10.18074/ckuiibfd.493177

Cole, M,S., Brunch, H. and Vogel, B. (2006). Emotion as mediators of the relations between perceived supervision support and psychological hardiness on employee cynicism. Journal of Organizational Behavior, (27), 463-484. https://doi.org/10.1002/job.381

Çalışkan, S. C. (2014). Pozitif örgütsel davranış değişkenleri ile yeni araştırma modelleri geliştirme arayışları: pozitif örgütsel davranış değişkenlerinin işe adanmışlık, tükenmişlik ve sinizm üzerine etkileri ve bu etkileşimde örgütsel adalet algısının aracılık rolü üzerine bir araştırma. Dokuz Eylül Üniversitesi Sosyal Bilimler Enstitüsü Dergisi, 16(3), 363-382. https://doi.org/10.16953/deusbed.81606

Çıkmaz, G. ve Yeşil, S. (2020). Çalışanların algıladıkları örgütsel desteğin psikolojik sahiplenme üzerine etkisi, Opus-Uluslararası Toplum Araştırmaları Dergisi, 15(22), 1234-1254. https://doi.org/10.26466/opus.658193

Çiftçi, G. E. ve Çankaya, M. (2019). İşkoliklik ve benlik saygısı arasındaki ilişkide örgütsel desteğin aracılık rolü: sağlık sektöründe bir araştırma, Akademik Incelemeler Dergisi, 14(1), 499-536. https://doi.org/10.17550/akademikincelemeler.464116

Dalay, G. (2007). The Relationship Between the Variables of Organizational Trust, Job Engagement, Organizational Commitment and Job Involvement. Yüksek Lisans Tezi. Marmara Üniversitesi Sosyal Bilimler Enstitüsü.

Dai, K. and Qin, X. (2016). Perceived organizational support and employee engagement: based on the research of organizational identification and organizational justice. Open Journal of Social Sciences, (4), 46-57. https://doi.org/10.4236/jss.2016.412005 
Demirel, E. T. (2013), Mesleki stresin iş tatminine etkisi: örgütsel desteğin arac1lık rolü, Niğde Üniversitesi İktisadi ve İdari Bilimler Fakültesi Dergisi, 6(1), 220-241.

Demirer, M. C. ve Polatcı, S. (2019). Örgütsel-sosyal destek ile duygusal zekânın iş ve yaşam tatmini üzerine etkisi: Bankacılık sektöründe bir uygulama, Çankırı Karatekin Üniversitesi İktisadi ve İdari Bilimler Fakültesi Dergisi, 9(2), 55-73. https://doi.org/10.18074/ckuiibfd.493177

Durmuş, B., Yurtkoru, S. E. ve Çinko, M. (2013). Sosyal bilimlerde SPSS'le veri analizi, Beta Yayınları, İstanbul.

Düzgün, E. ve Yeşiltaş, M. (2019). Otel işletmelerinde algılanan örgütsel destek ve örgütsel özdeşleşme arasındaki ilişkide psikolojik sermayenin aracılık etkisinin incelenmesi, Seyahat ve Otel Iş̧letmeciliği Dergisi, 16(3) https://doi.org/10.24010/soid.628745

Eisenberger, R. H., Robin Hutchison, S. and Debora, S. (1986). Perceived organizational supporot, Journal of Applied Psychology, 71(3), 500-507. https://doi.org/10.1037/00219010.71.3.500

Eisenberger, R., Armeli, S., Rexwinkel, B., Lynch, P. D. and Rhoades, L. (2001). Reciprocation of perceived organizational support, Journal of Applied Psychology, 86(1), 4251. https://doi.org/10.1037/0021-9010.86.1.42

Eisenberger, R., Cummings, J., Armeli, S. ve Lynch, P. D., (1997). Perceived organizational support, discretionary treatment, and job satisfaction, Journal of Applied Psychology, 82, 812-820. https://doi.org/10.1037/0021-9010.82.5.812

Güneşer, A. B. (2007). The effect of person-organization fit on organizational commitment and work engagement: the role of person supervisor fit. Doktora Tezi. Marmara Üniversitesi, Sosyal Bilimler Enstitüsü.

Güvenç, S. (2012). İşe yönelik destek ve çalışmaya tutkunluk arasındaki ilişki. Yüksek Lisans Tezi. Marmara Üniversitesi, Sosyal Bilimler Enstitüsü.

İnce, A. R. (2016). Algılanan örgütsel desteğin işe adanmışlık üzerindeki etkisinde yönetici desteğinin aracılık rolü, Elektronik Sosyal Bilimler Dergisi, 15(57), 649-660.

Janssen, O. (2000). Job Demands, perceptions of effort-reward fairness and innovative work behaviour. Journal of Occupational and Organizational Psychology; Leicester, 73, 287302. https://doi.org/10.1348/096317900167038

Kahn, W. A. (1990), Psychological conditions of personal engagement and disengagement at work, Academy of Management Journal, 33(4). https://doi.org/10.5465/256287

Kerse, G. ve Karabey, C. N. (2019). Örgütsel sinizm ve özdeşleşme bağlamında algilanan örgütsel desteğin işe bağlanma ve politik davranış algısına etkisi, Eskişehir Osmangazi Üniversitesi IIIBF Dergisi, 14(1), 83 - 108. https://doi.org/10.17153/oguiibf.439835

Kline, P. (1994). An easy guide to factor analysis. Routledge

Köse, A. (2015). İşe angaje olma ile örgütsel destek algısı ve örgüt iklimi arasındaki ilişki Kahramanmaraş ili örneği). Doktora Tezi. Kahramanmaraş Sütçü İmam Üniversitesi.

Lee, J. and Peccei, R. (2007), Perceived organizational support and affective commitment: the mediating role of organization-based self-esteem in the context of job insecurity. Journal of Organizational Behavior, 28, 661-685. https://doi.org/10.1002/job.431

Leiter, M. P. and Bakker, A. B. (2010). Work engagement: Introduction. In A. B. Bakker (Ed.) Leiter, M. P. Work engagement: A handbook of essential theory and research, 1-9. 
Meriç, E., Öztürk Çiftci, D. ve Yurtal, F. (2019). Algılanan örgütsel destek ve işe adanmışlık arasındaki ilişkinin incelenmesi, Kastamonu Education Journal, 27(1), 65-74. https://doi.org/10.24106/kefdergi.2296

Mert, İ. S. ve Şen, C. (2019). Örgütsel destek, örgütsel adalet ve öz kendilik değerlendirmesinin psikolojik sermaye üzerindeki etkisi. Pamukkale Üniversitesi Sosyal Bilimler Enstitüsü Dergisi, (36), 213-231. https://doi.org/10.30794/pausbed.533963

Murthy, R. (2017). Perceived organizational support and work engagement. International Journal of Applied Research, 5(3), 738-740.

Ngo, H. Y., Loi, R., Foley, S., Zheng, X. and Zhang, L. (2013). Perceptions of organizational context and job attitudes: the mediating effect of organizational 1dentification, Asiapac $J$ Management, 30, 149-168. https://doi.org/10.1007/s10490-012-9289-5

Önderoğlu, S. (2010). Örgütsel adalet algısı, iş aile çatışması ve algılanan örgütsel destek arasındaki bağlantılar, Yüksek Lisans Tezi, Ankara Üniversitesi Sosyal Bilimler Enstitüsü.

Öner, Z. H. (2008). The Mediating Effect of Organizational Justice: Moderating Roles of Sende of Coherence and Job Complexity on the Relationship Between Servant Leaders - Hip and Work Engagement. Doctoral Thesis. Marmara University.

Örücü, E. ve Uçku, İ. (2019), Örgütlerde işe tutkunluk, örgütsel destek algısı, örgütsel vatandaşlık davranışı ilişkisi ve bir araştırma, Çă̆ Üniversitesi Sosyal Bilimler Dergisi, 16(2), 71-81. https://dergipark.org.tr/tr/pub/cagsbd/issue/51317/668646

Özdemir, A. (2010). Örgütsel özdeşleşmenin algılanan örgütsel destek, cinsiyet ve kıdem değişkenlerine göre incelenmesi, TSA Dergisi, 14(1), 238-250.

Özdemir, B. Özcan, H. M. ve Yalçınkaya, A. (2019). Algılanan örgütsel destek ve çalışmaya tutkunluk arasındaki ilişkide örgütsel güvenin aracı rolü: akademisyenler üzerine bir araştırma, Bilecik Şeyh Edebali Üniversitesi Sosyal Bilimler Enstitüsü Dergisi, 4(2), 706724. https://doi.org/10.33905/bseusbed.640815

Özdevecioğl1, M. (2003). Algılanan örgütsel destek ile örgütsel bağl1lık arasındaki ilişkilerin belirlenmesine yönelik bir araştırma, D.E.Ü.I.I.B.F. Dergisi, 18(2), 113-130.

Özer, Ö., Saygılı, M., Uğurluoğlu, Ö. (2015). Sağlık çalışanlarının işe cezbolma düzeylerinin belirlenmesine ilişkin bir araştırma. Business \& Management Studies: An International Journal, 3(3), 261-272. http://dx.doi.org/10.15295/bmij.v3i3.115

Özkara, Z. U., Taş, A. ve Aydıntan, B. (2019). Algılanan yönetici desteği ile örgütsel sinizm arasındaki ilişkide lider-üye etkileşiminin aracılık etkisi. Opus-Uluslararası Toplum Araştırmaları Dergisi, 12 (18. UİK Özel Sayıs1). https://doi.org/10.26466/opus.584036

Özdişçi, S. ve Katrancı, Y. (2019). Ortaokul düzeyinde geometriye yönelik bir tutum ölçeğinin geliştirilmesi, Kastamonu Education Journal, 27(4), 1563-1573. https://doi.org/10.24106/kefdergi.3152

Pierce, J. L., Kostova, T. and Dirks, K. (2003). The state of psychological ownership: integrating and extending a century of research, Review of General Psychology, 7(1), 84-107. https://doi.org/10.1037/1089-2680.7.1.84

Prathiba, S. (2016). A study on 1mpact of employee empowerment and amployee engagement on organizational commitment, Sies Journal of Management, 12(2), 45-54. 
Rhoades, L. and Eisenberger, R. (2002). Perceived organizational support: a review of the literature, Journal of Applied Psychology, 87 (4), 698-714. https://doi.org/10.1037/00219010.87.4.698

Roberts, D. R. and Davenport, T. O. (2002). Job engagement: why it's important and how to improve it, Employment Relations Today, 29(3), 21-29. https://doi.org/10.1002/ert.10048

Saks, A. M. (2006). Antecedents and consequences of employee engagement, Journal of Managerial Psychology, 21(7), 600-19. https://doi.org/10.1108/02683940610690169

Schaufeli, W. B., Salanova, M., González-Romá, V. and Bakker, A. B. (2002), The measurement of engagement and burnout: a two sample confirmatory factor analytic approach, Journal of Happiness Studies, 3(1), 71-92. https://doi.org/10.1023/A:1015630930326

Schaufeli, W. and Bakker, A. B. (2004), Job Demands, job resources, and their relationship with burnout and engagement: a multi-sample study, Journal of Organizational Behavior, (25), 293-315. https://doi.org/10.1002/job.248

Schaufeli W., Taris, T. W. and Van Rhenen, W. (2008), Workaholism, burnout, and work engagement: three of a kind or three different kinds of employee well-being? Applied Psychology: An International Review, 57 (2), 173-203. https://doi.org/10.1111/j.14640597.2007.00285.x

Seçilmiş, C., Düşmezkalendar, E. ve Özhasar, Y. (2019). Kriz ve meslekten ayrılma niyeti ilişkisi: algılanan örgütsel desteğin aracılık rolü, Bartın Üniversitesi İktisadi ve İdari Bilimler Fakültesi Dergisi, https://dergipark.org.tr/en/pub/bartiniibf/issue/50408/603776

Selçuk, G. (2003). Örgütsel Desteğin Çalışanların İş ile İlgili Tutumlarına Etkisi. Yüksek Lisans Tezi. Dokuz Eylül Üniversitesi Sosyal Bilimler Enstitüsü.

Serinikli, N. (2019). Çalışanların örgütsel destek algılarının iş tatminlerine etkisinde iş stresinin aracıl1k rolü, Gümüşhane Üniversitesi Sosyal Bilimler Enstitüsü Elektronik Dergisi, 10 (3), 585-597. https://dergipark.org.tr/tr/pub/gumus/issue/49667/487181

Singh, A. and Singh, A. P. (2010). Role of stress and organizational support in predicting organizational citizenship behavior, IUP Journal of Organizational Behavior, 9(4), 7-25. https://doi.org/10.13140/2.1.1736.7689

Sluss, D. M., Klımchak, M. and Holmes, J. J. (2008). Perceived organizational support as a mediator between relational exchange and organizational identification, Journal of Vocational Behavior, 73, 457-464. https://doi.org/10.1016/j.jvb.2008.09.001

Sonnentag, S. (2003). Recovery, work engagement and proactive behavior: a new look at the interface between nonwork and work. Journal of Applied Psychology, 88(3), 518-528. https://doi.org/10.1037/0021-9010.88.3.518

Stamper, C. L. and Johlke, M. C. (2003). The impact of perceived organizational support on the relationship between boundary spanner role stress and work outcomes. Journal of Management, 29(4), 569-588. https://doi.org/10.1016/S0149-2063_03_00025-4

Sü-Eröz, S. ve Şıttak, S. (2019). Konaklama işletmelerinde algılanan örgütsel destek ve yenilikçi iş davranışı arasındaki ilişki. Opus-Uluslararası Toplum Araştırmaları Dergisi, 13(19), 1574-1599. https://doi.org/10.26466/opus.578547

Tabachnick, B. ve Fidell, L. (2013). Using Multivariate Statistics, Pearson.

Turgut, H. (2014). Algılanan örgütsel desteğin işletme performansına etkisinde iç girişimciliğin aracılık rolü, İsletme Araştırmaları Dergisi, 6(3), 29-62. 
Turgut, T. (2011). Çalışmaya tutkunluk: iş yükü, esnek çalışma saatleri, yönetici desteği ve iş-aile çatışması ile ilişkileri. Atatürk Üniversitesi İktisadi ve İdari Bilimler Dergisi, 25 (3-4) , 155179. https://dergipark.org.tr/tr/pub/atauniiibd/issue/2703/35540

Turgut, T. (2013). Başarı hedef yönelimleri ve iş özelliklerinin çalışmaya tutkunluk üzerindeki katkıları, İstanbul Üniversitesi İşletme Fakültesi Dergisi, 42(1), 1-25. https://dergipark.org.tr/tr/pub/iuisletme/issue/9257/115800

Turunç, Ö. ve Çelik, M. (2010). Çalışanların algıladıkları örgütsel destek ve iş stresinin örgütsel özdeşleşme ve iş performansına etkisi, Yönetim ve Ekonomi Dergisi, 17(2), 183-206.

Uzunbacak, H. H., Akçakanat, T. ve Çarıkçı, İ. H. (2018). Lider-üye etkileşimi ile yenilikçi iş davranış1 arasındaki ilişkide algılanan örgütsel desteğin ve işe adanmışlığın rolü. 6 . Örgütsel Davranış Kongresi Bildiriler Kitabı, 17-29.

Yavan, Ö. (2016). Örgütsel davranış düzleminde adanmışlık. Pamukkale Üniversitesi Sosyal Bilimler Enstitüsü Dergisi, $\quad$ (25), 278-296. https://dergipark.org.tr/en/pub/pausbed/issue/34751/384348

Yılmaz, H. ve Görmüş, A. (2012). Stratejik girişimciliğin, algılanan örgütsel destek ve örgütsel öğrenme üzerine etkilerinin araştırılması: tekstil sektöründe ampirik bir çalışma, Journal $\begin{array}{llll}\text { of Yaşar } & \text { University, 26(7), 4483-4504. }\end{array}$ https://dergipark.org.tr/tr/pub/jyasar/issue/19138/203094 